\title{
Rapid development of metastatic pulmonary calcifications in primary hyperparathyroidism: a case report and literature review
}

\author{
Hui-ming Sun ${ }^{1}$, Fei Chen ${ }^{1}$, Hong-lin Yin², Xiao-yong Xu' ${ }^{1}$, Hong-bing Liu ${ }^{1}$ and Bei-lei Zhao ${ }^{\text {** }}$
}

\begin{abstract}
Background: Metastatic pulmonary calcification (MPC) is rarely reported in primary hyperparathyroidism, especially MPC develops quickly. We report such a case here with a literature review.

Case presentation: A 41-year-old woman presented with cough and dyspnea. Data from clinical, radiological, pathological, technetium $\left({ }^{99 \mathrm{~m}} \mathrm{Tc}\right.$ )-methylene diphosphonate (MDP) bone scintillation imaging, and ${ }^{99 \mathrm{~m}} \mathrm{Tc}$-methoxy isobutyl isonitrile (MIBI) thyroid imaging were studied. ${ }^{99 \mathrm{~m}} \mathrm{Tc}-\mathrm{MIBI}$ thyroid imaging indicated hyperparathyroidism. Chest computed tomography (CT) scans showed rapidly progressive bilateral pulmonary multiple high-density shadows with mass consolidation and exudation in only five days. ${ }^{99 \mathrm{~m}} \mathrm{Tc}-\mathrm{MDP}$ bone scintillation imaging indicated bilateral pulmonary calcifications. CT-guided lung biopsy showed multifocal irregularities of calcium deposition and calcified bodies in the pulmonary interstitium. The patient showed gradually clinical and radiological improvement after surgical removal of the parathyroid adenoma.
\end{abstract}

Conclusion: Rapidly progressive MPC tends to be misdiagnosed as many primary pulmonary diseases. ${ }^{99 \mathrm{~m}} \mathrm{Tc}-\mathrm{MDP}$ bone scintillation imaging and pulmonary biopsy could be performed to differentiate metastatic pulmonary calcification from other diseases. Surgical resection of the parathyroid gland is helpful for treatment of MPC in patients with primary hyperparathyroidism and is regularly recommended.

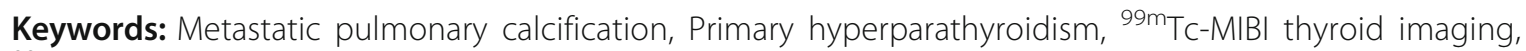
${ }^{99 \mathrm{~m} T c-M D P}$ bone scintillation imaging

\section{Background}

Primary hyperparathyroidism is typically characterized by disorders of calcium-phosphate and bone metabolism associated with inappropriately elevated parathyroid hormone levels, which is caused by lesions of the parathyroid glands that can be classified as adenoma, glandular hyperplasia, or carcinoma $[1,2]$. Calcium deposition in normal pulmonary parenchyma due to abnormal calcium metabolism can cause metastatic pulmonary calcifications (MPC). MPC tends to be misdiagnosed as one of many primary pulmonary diseases,

\footnotetext{
*Correspondence: zhaobeil2002@126.com

'Department of Respiratory and Critical Care Medicine, Jinling Hospital,

Nanjing, Jiangsu Province 210002, China

Full list of author information is available at the end of the article
}

leading to a delay in appropriate treatment of the illness [3-5]. Rapid development of MPC in primary hyperparathyroidism is rarely reported. In this study, we present such a case with a review of literature.

\section{Case presentation}

A 41-year-old woman who presented with nausea and vomiting for about six months and cough and chest discomfort for two days was admitted to a local medical center. Laboratory tests showed the serum $\mathrm{Ca}^{2+}$ level at $3.49 \mathrm{mmol} / \mathrm{L}$ and parathyroid hormone at $78.7 \mathrm{pmol} / \mathrm{L}$. The ${ }^{99 \mathrm{~m}} \mathrm{Tc}$-sestamethoxyisobutylisonitrile (MIBI) thyroid imaging indicated hyperparathyroidism (Fig. 1). A chest computed tomography (CT) scan showed bilateral pulmonary mild linear opacities (Fig. 2a, b). The patient 


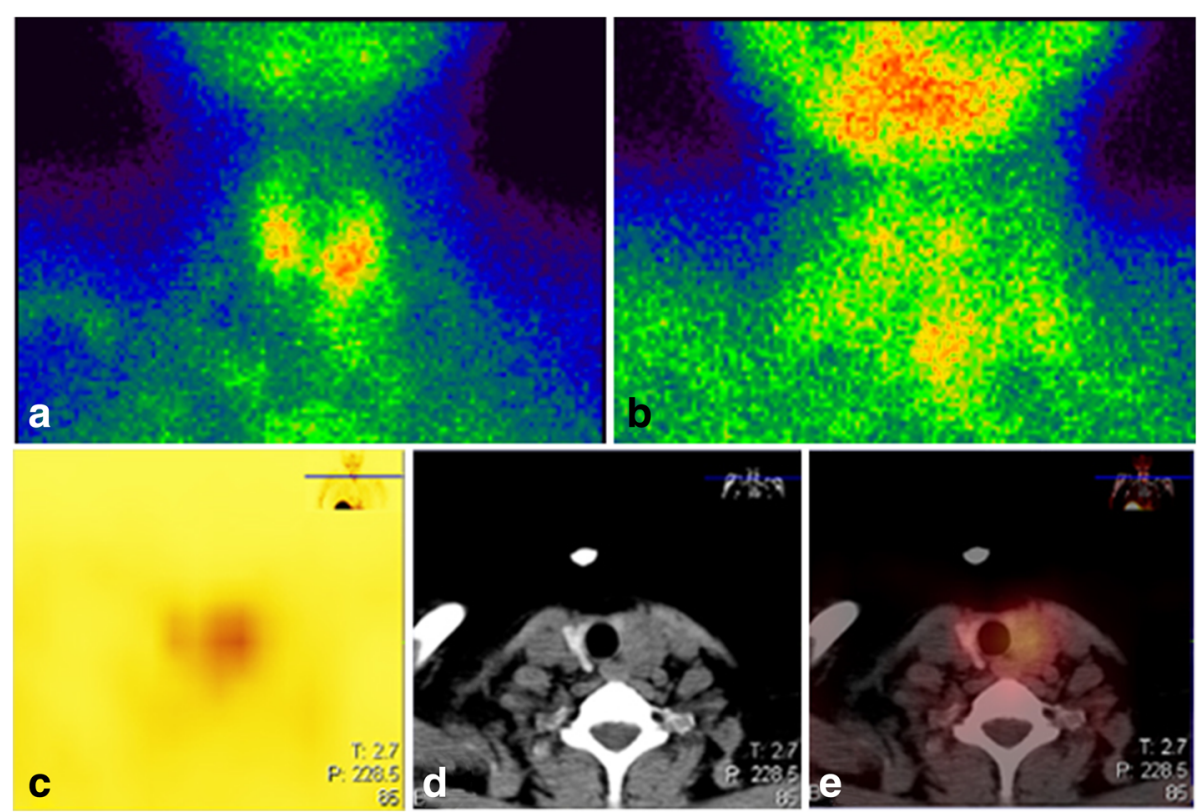

Fig. 1 Representative ${ }^{99 m} \mathrm{Tc}-\mathrm{MIBI}$ thyroid images indicative of hyperparathyroidism. The patient was intravenously injected with $740-925 \mathrm{MBq}{ }^{99 m} \mathrm{Tc}-\mathrm{MIBI}$. A single-photon emission (SPECT)/CT instrument was used, which was equipped with a parallel low-energy high-resolution collimator with an energy peak of $140 \mathrm{keV}$ and a window width of $20 \%$. The magnification when performing the neck scan was 1.5 -fold, with a matrix of $128 \times 128$ pixels and an acquisition count of $1000 \mathrm{~K}$ at $10 \mathrm{~min}$ and an acquisition count of $682 \mathrm{~K}$ at $120 \mathrm{~min}{ }^{99 \mathrm{~m}} \mathrm{Tc}-\mathrm{MIBI}$ injection. Two points have the same acquisition time of $600 \mathrm{~s}$. Neck systemic planar images were obtained after $10 \mathrm{~min} \mathbf{a}$ and $120 \mathrm{~min} \mathbf{b}$; c-e There is a soft tissue nodule located in the posterior lobe of the left thyroid gland, with radioactive accumulation

was prepared for surgical resection of left parathyroid. Her symptoms suddenly became worse with fever and dyspnea. The surgery was cancelled and a chest CT scan was performed again (Fig. 2c, d), which showed a bilateral pulmonary multiple high-density shadow with mass consolidation and exudation that had progressed greatly over the intervening five days. She was then transferred and admitted to our Respiratory Intensive Care Unit.

The significant abnormal data for routine blood tests are shown in Table 1 . The patient was diagnosed with severe pneumonia and was administered broad-spectrum antibiotics. Her body temperature returned to normal, but the symptoms of chest discomfort were still obvious. The chest CT was re-examined after two weeks of treatment, which showed obvious calcifications in the bilateral lungs (Fig. 2e, f). Therefore, the patient received a CT-guided cutting-needle lung biopsy of the left pulmonary. The histopathological results indicated pulmonary fibrosis and interalveolar septa broadening with multifocal calcium deposition and irregular-shaped calcified bodies. No obvious inflammatory cell or giant cell reaction was observed in pulmonary interstitium (Fig. 3a, b). ${ }^{99 m}$ Tc-methylene

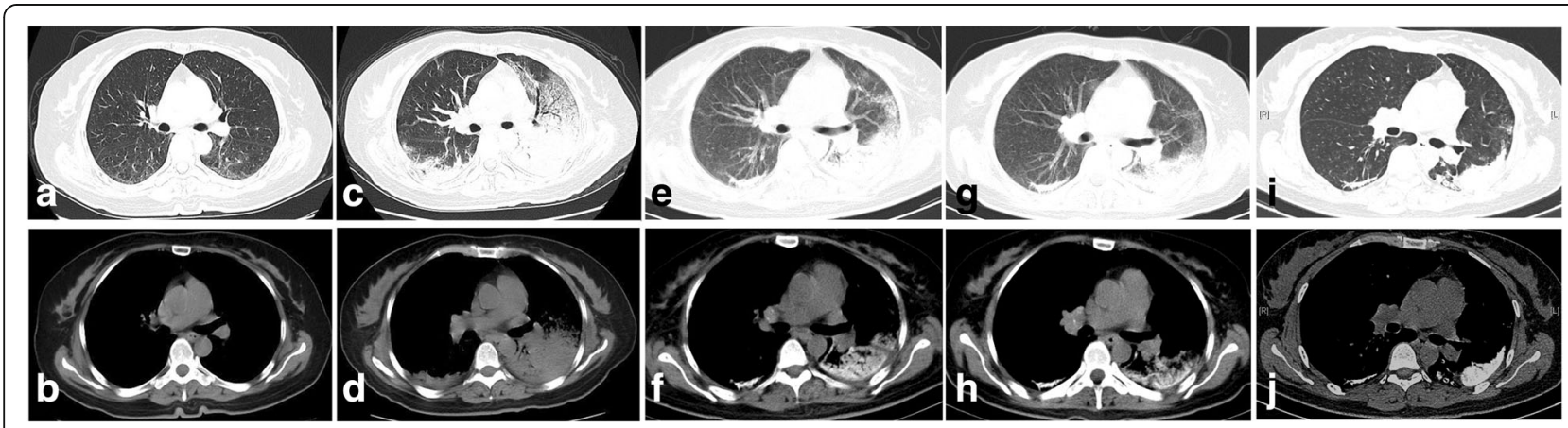

Fig. $\mathbf{2}$ CT scanning of the chest. a, b Initial CT scans: A little linear opacity on the bilateral pulmonary. c, d CT scans five days later: Bilateral pulmonary multiple high-density shadow with mass consolidation and exudation; obvious progression when compared with initial scan. e, f Chest image after treatment of two weeks: Obvious calcification in bilateral lungs. $\mathbf{g}, \mathbf{h}$ Chest CT after left parathyroidectomy: Lesions were mildly improved. $\mathbf{i}, \mathbf{j}$ Pulmonary calcifications did not deteriorate or improve 8 months later in the follow-up examination 
Table 1 Significant abnormal laboratory data

\begin{tabular}{llll}
\hline Laboratory studies & & Data & Reference values \\
\hline Hematological test & WBC & $10.7 \times 10^{9} / \mathrm{L}$ & $4.0-10.0 \times 10^{9} / \mathrm{L}$ \\
& Neutrophils & $8.8 \times 10^{9} / \mathrm{L}$ & $1.5-6.0 \times 10^{9} / \mathrm{L}$ \\
& Hemoglobin & $90 \mathrm{~g} / \mathrm{L}$ & $120-175 \times 10^{9} / \mathrm{L}$ \\
& RBC & $2.83 \times 10^{12} / \mathrm{L}$ & $4.0-5.5 \times 10^{12} / \mathrm{L}$ \\
& ESR & $102 \mathrm{~mm} / \mathrm{h}$ & $0-15 \mathrm{~mm} / \mathrm{h}$ \\
Blood biochemical test & BUN & $11.3 \mathrm{mmol} / \mathrm{L}$ & $2.9-8.2 \mathrm{mmol} / \mathrm{L}$ \\
& Albumin & $23.2 \mathrm{~g} / \mathrm{L}$ & $40-55 \mathrm{~g} / \mathrm{L}$ \\
& Serum calcium & $2.75 \mathrm{mmol} / \mathrm{L}$ & $2.0-2.6 \mathrm{mmol} / \mathrm{L}$ \\
& PTH & $59.5 \mathrm{pmol} / \mathrm{L}$ & $1.3-9.5 \mathrm{pmol} / \mathrm{L}$ \\
Inflammation profile & CRP & $134.6 \mathrm{mg} / \mathrm{L}$ & $0-10.0 \mathrm{mg} / \mathrm{L}$ \\
& PCT & $8.93 \mu \mathrm{mol} / \mathrm{L}$ & $<0.05 \mu \mathrm{mol} / \mathrm{L}$ \\
Coagulation profile & PT & $15.3 \mathrm{~s}$ & $9-14 \mathrm{~s}$ \\
& INR & 1.32 & $0.80-1.20$ \\
& Fibrinogen & $6.87 \mathrm{~g} / \mathrm{L}$ & $2.0-4.0 \mathrm{~g} / \mathrm{L}$ \\
& D-dimer & $4.97 \mathrm{mg} / \mathrm{L}$ & $<0.5 \mathrm{mg} / \mathrm{L}$ \\
\hline
\end{tabular}

WBC white blood cell, $R B C$ red blood cell, ESR erythrocyte sedimentation rate, $B U N$ blood urea nitrogen, $P T H$ parathyroid hormone, CRP C-reactive protein, $P C T$ procalcitonin, PT prothrombin time, INR international normalized ratio diphosphonate (MDP) bone scintillation imaging indicated bilateral pulmonary calcification (Fig. 4). The patient received a left parathyroid gland resection. The histopathology showed the nest-like distribution of parathyroid tumor cells, which were round or columnar with the cytoplasm being transparent and the nucleus being round or oval. Neither nucleus atypia nor mitotic activity was observed. Branched blood vessels were found between the cells and there was no tumor necrosis. The pathological diagnosis was left parathyroid adenoma (Fig. 3c, d). The patient's serum $\mathrm{Ca}^{2+}$ and parathyroid hormone levels declined to normal soon after the surgery, and her chestrelated symptoms improved gradually. Re-examination of chest CT scans (2 weeks after the operation) (Fig. $2 \mathrm{~g}, \mathrm{~h}$ ) showed that the lesions, including the calcifications, were mildly improved, whereas the pulmonary calcifications did not deteriorate or improve 8 months later in the followup examination (Fig. 2i, j).

\section{Discussion}

The majority of patients with MPC suffer from secondary hyperparathyroidism and typically chronic renal failure
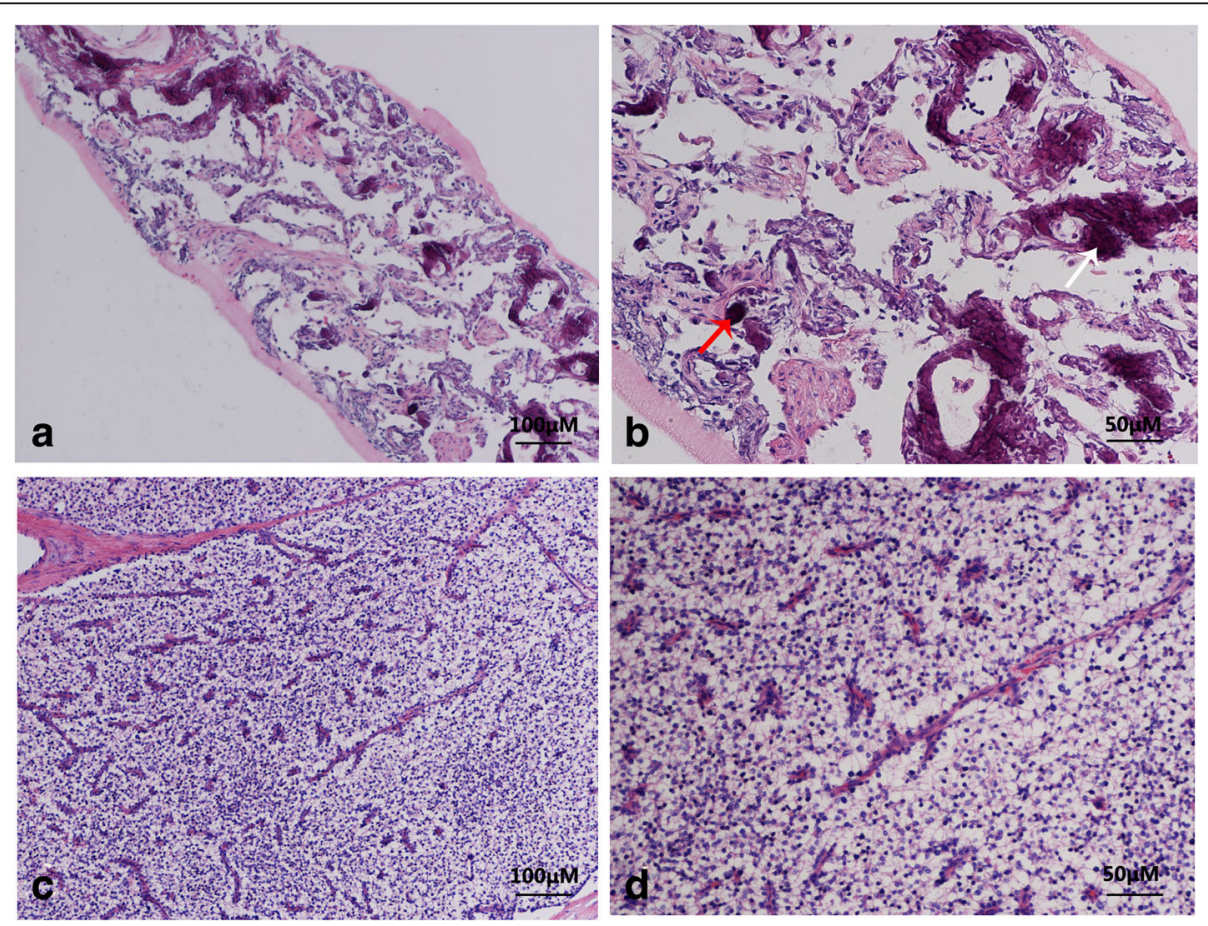

Fig. 3 Representative hematoxylin and eosin (H\&E) staining of tissue sections from CT-guided biopsy of left pulmonary $\mathbf{a}$, $\mathbf{b}$ and left parathyroidectomy $\mathbf{c}$, $\mathbf{d}$. a The alveoli structure was partially damaged. Fibrosis and interalveolar septa broadening were seen in the pulmonary interstitium with multifocal calcium deposition and irregular-shaped calcified bodies. No obvious inflammatory cell or giant cell reaction was observed in pulmonary interstitium $(H \& E 100 \times$.). b Multifocal irregularities of calcium deposition and the calcified bodies in the pulmonary interstitium were seen at high magnification (white arrow), some of which resemble the psammoma bodies seen in a thyroid gland papillary carcinoma (red arrow) (H\&E $200 \times$.). c Tumor cells were shown as the organ-like tissue structure and the tumor cells were in the nest-like distribution. Branched blood vessels were found between the cells and no tumor necrosis was observed (H\&E $100 \times$.). d High magnification revealed the nest-like distribution of tumor cells, which were round or columnar with the cytoplasm being transparent and the nucleus being round or oval. Neither nucleus atypia nor mitotic activity was observed. Sinusoid segmentation could be found between the tumor cells (H\&E $200 \times$.) 


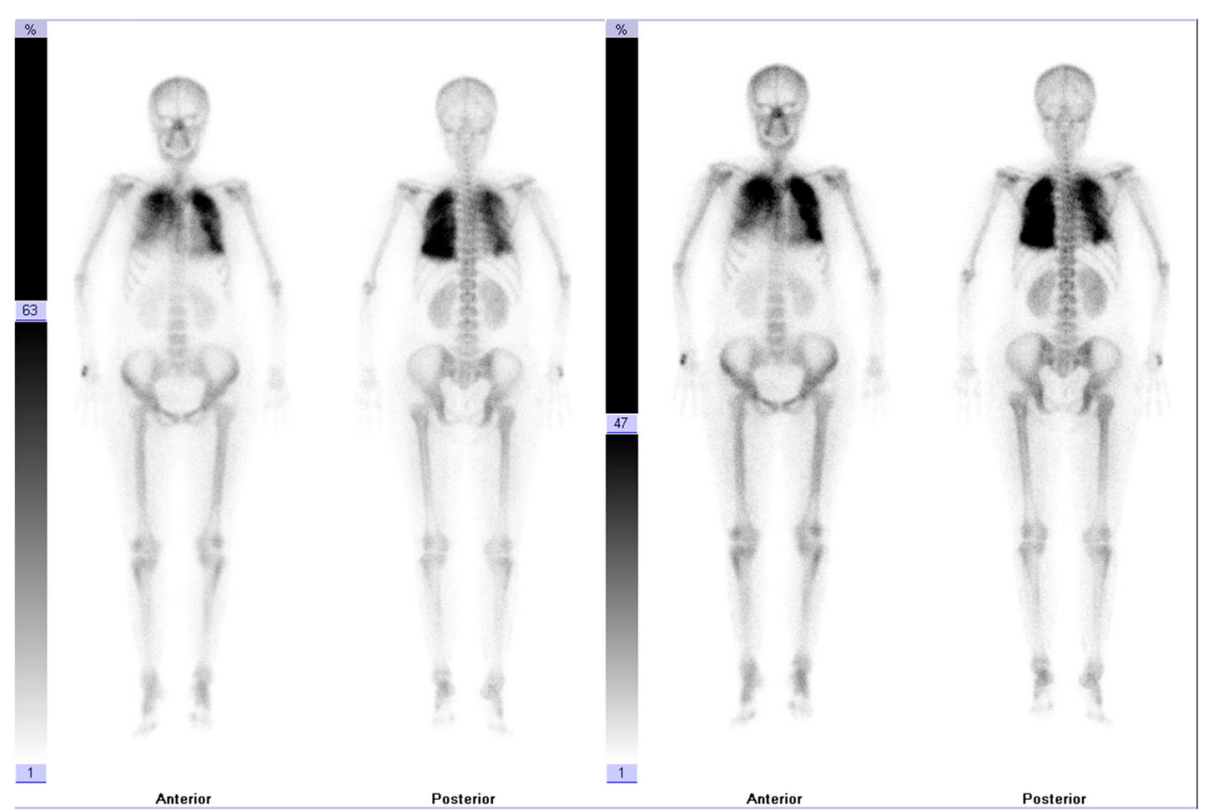

Fig. 4 Representative ${ }^{99 m} \mathrm{Tc}-M D P$ bone scintillation images showing pulmonary calcification. The patient was intravenously injected with $740-925 \mathrm{MBq}$

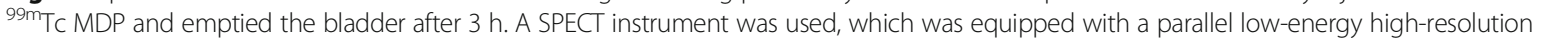
collimator. Anterior and posterior views were imaged at same time with scanning speeds of $15-20 \mathrm{~cm} / \mathrm{min}$ and matrix $1024 \times 256$ pixels

[6-9]. It was reported that at autopsy, 60-80 percent of long-term hemodialysis patients exhibited MPC, with most of these cases not being recognized during life [9]. However, there are few cases that report MPC in patients with primary hyperparathyroidism and the reason for this remains unclear. The case we report here involved a delayed diagnosis of parathyroid adenoma, which was eventually identified by histopathology. Given that most patients with primary hyperparathyroidism who suffer from adenoma, glandular hyperplasia, or carcinoma would receive surgeries shortly after the diagnosis was established, mostly at an early stage $[1,2]$, there might not be sufficient time for the pathogenetic development of MPC.

The underlying pathogenic mechanism of MPC is not yet well understood. Most studies suggest that disruption in the metabolism of calcium and phosphate contribute to MPC $[3,7,9]$. MPC may occur when calcium-phosphate products exceed $40 \mathrm{mg} / \mathrm{dl}^{2}[10,11]$. Long-term disorders of calcium and phosphate may lead to parathyroid hyperplasia, which will secrete more parathyroid hormone to balance the electrolyte concentrations. It is difficult for kidneys to excrete excess calcium; therefore, excess calcium will be deposited in tissues and organs, including lungs [3]. Similar to the majority of reported cases, both hypercalcemia and a high level of parathyroid hormone were observed in the present patient. However, MPC has also been reported in patients with normal calcium and phosphate levels, normal parathyroid hormone, and normal renal function [3, 12].
Because metastatic calcifications are frequently found in lung, kidney, and stomach, it has been noted that the secretion of free hydrogen ions is an important local factor in the development of metastatic calcification. These organs secrete lots of free hydrogen ions and create an alkaline environment, which can induce the deposition of calcium salts [13, 14].

Although MPC generally progresses gradually, it may also develop relatively quickly within a short period of time, from several weeks to months $[4,15]$. In the present case the MPC developed very rapidly, in only five days, which has been rarely reported before. The factors that trigger such aggressive development of MPC remain unidentified, although reports suggest that hypercalcemia or unsuccessful renal transplantation may play an important role in the development of severe MPC [16, 17]. Thurley and his colleagues [18] once reported a patient with chronic renal failure who suffered rapidly progressive MPC and mentioned that chest infection might be a contributory factor for rapid progression. The present patient suffered a similar experience for she contracted a mild cold after admission. Therefore, respiratory infection combined with hypercalcemia may have activated the rapid development of MPC in the present patient.

The majority of the patients with MPC are asymptomatic and have a favorable prognosis [19]. While the minority of patients who develop MPC rapidly sometimes exhibit severe respiratory distress that can lead to death $[4,8]$. The rapid development of MPC is characterized by 
a progressive chest shadow that can be visible on highresolution CT (HRCT). This shadow is often described as multiple diffuse nodules, diffuse or patchy areas of groundglass opacities, and confluent parenchymal consolidations, which is easily misdiagnosed as severe pneumonia or pulmonary edema $[4,8,19,20]$, as seen in the present case. In these cases, treatments with antibiotics, hormone, diuretics, or digitalis are not warranted. The relative stability of pulmonary consolidations and no reaction to the antibiotics might be useful to differentiate MPC from infectious pneumonia. In these circumstances, a pulmonary biopsy and $99 \mathrm{mTc}-\mathrm{MDP}$ bone scintillation imaging should be taken to establish the diagnosis of MPC.

Surgical parathyroidectomy is an effective strategy to treat MPC in the patients with primary hyperparathyroidism and secondary hyperparathyroidism with parathyroid hyperplasia [1, 21-23]. Following parathyroid resection, the MPC is often mildly absorbed and does not deteriorate. However, this approach is unlikely to completely absorbed large calcification deposit in the lung [3]. In our case, it was observed that the pulmonary calcifications were mildly absorbed 2 weeks after the operation and no additional improvement was observed over the following 8 months. However, in rare cases continued absorption may occur. Gui and his colleagues [24] reported a case with parathyroid adenoma in which pulmonary calcified lesions were significantly absorbed 11 months after surgical parathyroidectomy. Other therapies for MPC are limited. Normalizing the imbalance of calcium and phosphate during dialysis and discontinuing vitamin $\mathrm{D}$ supplements have been suggested and may be effective to some extent $[12,25]$.

\section{Conclusion}

In summary, the rapid development of MPC in primary hyperparathyroidism is rare and it is easily misdiagnosed as primary pulmonary disease. ${ }^{99 \mathrm{~m}} \mathrm{Tc}$-MDP bone scintillation imaging and pulmonary biopsy can be used to differentiate MPC from other diseases. Surgical resection of the parathyroid gland is helpful to treat MPC in patients with primary hyperparathyroidism and is regularly recommended.

\footnotetext{
Abbreviations

CT: Computed tomography; HRCT: High-resolution CT; MDP: Methylene diphosphonate; MIBI: Methoxy isobutyl isonitrile; MPC: Metastatic pulmonary calcification
}

\section{Acknowledgments}

The authors would like to appreciate Dr. Dong-mei Yuan and Dr. Yan-wen Yao for their constructive comments on this work.

\section{Funding}

This work was supported by the National Natural Science Foundation of China (81302032 to Hong-bing Liu).

\section{Authors' contributions}

CF acquired the medical report of the patient. Analysis and interpretation of data were performed by SHM, CF, XXY, LHB and ZBL. YHL explained the histopathological results. XXY and LHB reviewed the Literature. SHM drafted the paper. All authors read and approved the final paper.

\section{Competing interests}

The authors declare that they have no competing interests.

\section{Consent for publication}

Written informed consent for publication of the clinical details and the clinical images was obtained from the patient. A copy of the consent form is available for review by the editor of this journal.

Ethics approval and consent to participate

Not applicable.

\section{Publisher's Note}

Springer Nature remains neutral with regard to jurisdictional claims in published maps and institutional affiliations.

\section{Author details}

${ }^{1}$ Department of Respiratory and Critical Care Medicine, Jinling Hospital, Nanjing, Jiangsu Province 210002, China. ${ }^{2}$ Department of Pathology, Jinling Hospital, Nanjing, Jiangsu Province 210002, China.

Received: 27 January 2017 Accepted: 20 April 2017

Published online: 08 May 2017

\section{References}

1. Shindo M, Lee JA, Lubitz CC, McCoy KL, Orloff LA, Tufano RP, et al. The Changing Landscape of Primary, Secondary, and Tertiary Hyperparathyroidism: Highlights from the American College of Surgeons Panel, "What's New for the Surgeon Caring for Patients with Hyperparathyroidism". J Am Coll Surg. 2016:222(6):1240-50. doi:10.1016/j.jamcollsurg.2016.02.024.

2. Madkhali T, Alhefdhi A, Chen H, Elfenbein D. Primary hyperparathyroidism. Ulus Cerrahi Derg. 2016:32(1):58-66. doi:10.5152/UCD.2015.3032.

3. Liang Z, Qiu T, Zhao Z, Chen L, She D. Metastatic pulmonary calcification misdiagnosed as a fungal infection: A case report. Mol Clin Oncol. 2016:4(3):409-12. doi:10.3892/mco.2015.723.

4. Neff M, Yalcin S, Gupta S, Berger H. Extensive metastatic calcification of the lung in an azotemic patient. Am J Med. 1974;56(1):103-9.

5. Marchiori E, Souza Jr AS, Franquet T, Müller NL. Diffuse high attenuation pulmonary abnormalities: A pattern-oriented diagnostic approach on high-resolution CT. Am J Roentgenol. 2005;184(1):273-82. doi:10.2214/ ajr.184.1.01840273.

6. Belém LC, Zanetti G, Souza Jr AS, Hochhegger B, Guimarães MD, Nobre LF. Metastatic pulmonary calcification: State-of-the-art review focused on imaging findings. Respir Med. 2014;108(5):668-76. doi:10.1016/j.rmed.2014.01.012.

7. Kuzela DC, Huffer WE, Conger JD, Winter SD, Hammond WS. Soft tissue calcification in chronic dyalysis patients. Am J Pathol. 1977;86(2):403-24.

8. Mootz JR, Sagel SS, Roberts TH. Roentgenographic manifestations of pulmonary calcifications. A rare cause of respiratory failure in chronic renal disease. Radiology. 1973;107(1):55-60. doi:10.1148/107.1.55.

9. Hartman TE, Müller NL, Primack SL, Johkoh T, Takeuchi N, Ikezoe J, et al. Metastatic pulmonary calcification in patients with hypercalcemia: findings on chest radiographs and CT scans. Am J Roentgenol. 1994;162(4):799-802.

10. Ketteler M, Rothe H, Krüger T, Biggar PH, Schlieper G. Mechanisms and treatment of extraosseous calcification in chronic kidney disease. Nat Rev Nephrol. 2011;7(9):509-16. doi:10.1038/nrneph.2011.91.

11. Tristano AG. Metastatic calcification of the hand in a patient undergoing hemodialysis. Am J Med. 2004;116(18):572-3. doi:10.1016/j.amjmed.2003.10.042.

12. Ueno K, Shimizu M, Uchiyama A, Hatasaki K. Fulminant respiratory failure due to progressive metastatic pulmonary calcification with no predisposing factors after successful renal transplantation: A case report. Pediatr Transplant. 2016;20(8):1152-6. doi:10.1111/petr.12829.

13. Yasuo M, Tanabe T, Komatsu Y, Tsushima K, Kubo K, Takahashi K. Progressive pulmonary calcification after successful renal transplantation. Intern Med. 2008;47(3):161-4. 
14. Castaigne C, Martin P, Blocklet D. Lung, gastric, and soft tissue uptake of Tc-99m MDP and Ga-67 citrate associated with hypercalcemia. Clin Nucl Med. 2003;28(6):467-71. doi:10.1097/01.RLU.0000067505.24908.5C.

15. Cohen AM, Maxon HR, Goldsmith RE, Schneider HJ, Wiot JF, Loudon RG et al. Metastatic pulmonary calcification in primary hyperparathyroidism. Arch Intern Med. 1977;137(4):520-2.

16. Chan ED, Morales DV, Welsh CH, McDermott MT, Schwarz MI. Calcium deposition with or without bone formation in the lung. Am J Respir Crit Care Med. 2002;165:1654-69. doi:10.1164/rccm.2108054.

17. Murris-Espin M, Lacassagne L, Didier A, Voigt JJ, Cisterne JM, Giron J, et al. Metastatic pulmonary calcification after renal transplantation. Eur Respir J. 1997;10(8):1925-7.

18. Thurley PD, Duerden R, Roe S, Pointon K. Case report: Rapidly progressive metastatic pulmonary calcification: evolution of changes on CT. Br J Radiol. 2009:82(980):e155-9. doi:10.1259/bjr/87606661.

19. Marchiori E, Müller NL, Souza Jr AS, Escuissato DL, Gasparetto EL, de Cerqueira EM. Unusual manifestations of metastatic pulmonary calcification: high-resolution CT and pathological findings. J Thorac Imaging. 2005;20(2):66-70.

20. Sanders C, Frank MS, Rostand SG, Rutsky EA, Barnes GT, Fraser RG. Metastatic calcification of the heart and lungs in end-stage renal disease: Detection and quantification by dual-energy digital chest radiography. AJR Am JRoentgenol. 1987;149(5):88-7. doi:10.2214/aj.149.5.881

21. Ullmer $E$, Borer $H$, Sandoz P, Mayr M, Dalquen P, Solèr M. Diffuse pulmonary nodular infiltrates in a renal transplant recipient. Metastatic pulmonary calcification. Chest. 2001;120(4):1394-8.

22. Kitada M, Yasuda S, Nana T, Ishibashi K, Hayashi S, Okazaki S. Surgical treatment for mediastinal parathyroid adenoma causing primary hyperparathyroidism. J Cardiothorac Surg. 2016;11:44. doi:10.1186/s13019-016-0461-8.

23. Carnevale V, Romagnoli E, Pipino M, Scillitani A, D'Erasmo E, Minisola S, et al. Primary hyperparathyroidism. Clin Ter. 2005;156(5):211-26.

24. Gui X, Miao L, Cai H, Xiao Y, Zhang D, Wang J, et al. Primary hyperparathyroidism with metastatic pulmonary calcification: a case report and review of literature. Zhonghua jie he he hu xi za zhi. 2014;37(5):343-6.

25. Khafif RA, DeLima C, Silverberg A, Frankel R. Calciphylaxis and systemic calcinosis. Collective review. Arch Intern Med. 1990;150(5):956-9.

\section{Submit your next manuscript to BioMed Central and we will help you at every step:}

- We accept pre-submission inquiries

- Our selector tool helps you to find the most relevant journal

- We provide round the clock customer support

- Convenient online submission

- Thorough peer review

- Inclusion in PubMed and all major indexing services

- Maximum visibility for your research

Submit your manuscript at www.biomedcentral.com/submit
Biomed Central 